ISSN 0258-7122

Bangladesh J. Agril. Res. 37(4): 625-634, December 2012

\title{
SUITABILITY OF INTERCROPPING SESAME WITH MUKHIKACHU
}

\author{
M. R. ISLAM ${ }^{1,}$ M. A. K. MIAN ${ }^{2}$ AND M. T. RAHMAN ${ }^{3}$
}

\begin{abstract}
A field experiment was conducted at the Regional Agricultural Research Station, Ishurdi, Pabna, Bangladesh during 2008-09 and 2009-2010 to find out the suitable intercrop combination of sesame with mukhikachu for getting higher productivity and economic return. Five treatments comprised of $\mathrm{T}_{1}=$ sole mukhikachu (double row:20 cm/55 cm/20 cm $\times 45 \mathrm{~cm}$ ), $\mathrm{T}_{2}=$ sole sesame (30 $\mathrm{cm} \times 5 \mathrm{~cm}$ ), $\mathrm{T}_{3}=$ mukhikachu (double row:20 cm/55 cm/20 cm $\times 45 \mathrm{~cm}$ ) + one row sesame (30\%), $\mathrm{T}_{4}=$ mukhikachu (double row:20 cm/55 cm/20 cm $\times 45 \mathrm{~cm}$ ) + two row sesame $\left(60 \%\right.$ ), and $T_{5}=$ mukhikachu (double row:20 cm/55 cm/20 $\mathrm{cm} \times 45 \mathrm{~cm})+$ sesame broadcast $(100 \%)$. The results showed that intercropping systems affected the cormel yield of mukhikachu and seed yield of sesame. Mukhikachu yield decreased with the increase of sesame population in intercropped combination. The highest mean mukhikachu equivalent yield (15.65 t/ha), land equivalent ratio (1.83), gross return (Tk.187585/ha), gross margin (Tk. 114265/ha), and benefit cost ratio (2.56) were obtained from two rows of sesame $(30 \mathrm{~cm} \times 5 \mathrm{~cm})$ in between two double rows $(20 \mathrm{~cm} / 55 \mathrm{~cm} / 20$ $\mathrm{cm} \times 45 \mathrm{~cm}$ ) of mukhikachu. Sole crop of sesame gave the lowest mukhikachu equivalent yield (4.02 t/ha), gross return (Tk.48125/ha), gross margin (Tk. 19655/ha), and benefit cost ratio (1.69). Two years' study revealed that two rows of sesame (60\%) in between two double rows $(20 \mathrm{~cm} / 55 \mathrm{~cm} / 20 \mathrm{~cm} \times 45 \mathrm{~cm})$ of mukhikachu was found profitable intercropping combination.
\end{abstract}

Keywords: Intereropping, sesame, mukhikachu, sole crop, gross return.

\section{Introduction}

Intercropping is a common practice of crop cultivation to increase the productivity per unit area and ensure against total crop failures under aberrant weather conditions. Bangladesh is a densely populated country having 144.66 million people (AIS, 2011). Its cultivable area is decreasing day by day due to urbanization, increase of population, and industrialization. For such condition, our total food demand is also increasing. Intercropping is a system that can help to recover that demand to some extent. It increases total productivity per unit area through maximum utilization of land, labour, and growth resources (Marshall and Willey, 1983). It also increased land equivalent ratio (LER) to a varying degree (Hossain and Bari, 1996). Successful intercropping system gives higher cash

${ }^{1}$ Scientific Officer, ${ }^{2}$ Senior scientific Officer, Agronomy Division, Regional Agricultural Research Station, BARI, Ishurdi, Pabna, ${ }^{3}$ Scientific officer, Agronomy Division, Bangladesh Agricultural Research Institute (BARI), Gazipur, Bangladesh. 
return, total production per hectare, and diversifies production system than sole cropping (Kurala, 1966 and Yahock, 1979) and provides greater resources use efficiency (Pathick and Malla, 1979). Sesame (Sesamum indicum L.) competes with a number of crops like mungbean, jute, vegetables during the early Kharif season. Intercropping of sesame with mukhikachu is a way to avoid direct competition with other crops and to familiarize its potentiality to the farmers. The rate of mukhikachu emergence and subsequent growth are very slow. The emergence starts at 20-25 days after planting and it continues up to 50 to 55 days. Its growth becomes rapid at later stage when soil moisture is sufficient by rainfall. Sesame being a short duration (90-95 days) crop can be intercropped with long duration (210-280 days) wide spaced mukhikachu (Colocasia esculenta). They have also different growth habit and demand for growth resources. The return from intercropping is higher and more profitable than those from the relevant sole crop (Rao et al., 1979). So, if mukhikachu and sesame can be grown as intercrop, the farmers may be benefited economically. Some experimental findings on intercropping mukhikachu with sesame have been reported but suitable ratio is not as maintained. Hence, an experiment was undertaken to find out the suitability of intercropping sesame with mukhikachu for higher productivity and profitability at varying combinations.

\section{Materials and Method}

The experiment was conducted for two consecutive years of 2008-09 and 20092010 at the Regional Agricultural Research Station, Ishurdi, Pabna, Bangladesh. The soil of the experimental field was clay loam in texture belonging to Ishurdi series under the AEZ 11. During the growing period, monthly average maximum temperature ranged from 26.21 to $36.83{ }^{\circ} \mathrm{C}$ in $2008-09$ and 27.39 to $34.31^{\circ} \mathrm{C}$ in 2009-2010. The monthly minimum average temperature ranged from 21.11 to $27.67{ }^{\circ} \mathrm{C}$ in 2008-09 and 21.39 to $28.17^{\circ} \mathrm{C}$ in 2009-2010. Total monthly rainfall varied from 39.75 to $314.98 \mathrm{~mm}$ in 2008-2009 and 0.20 to $138.24 \mathrm{~mm}$ in 20092010. Treatments were viz., $T_{1}=$ sole mukhikachu (double row: $20 \mathrm{~cm} / 55 \mathrm{~cm} / 20$ $\mathrm{cm} \times 45 \mathrm{~cm}), \mathrm{T}_{2}=$ sole sesame $(30 \mathrm{~cm} \times 5 \mathrm{~cm}), \mathrm{T}_{3}=$ mukhikachu (double row:20 $\mathrm{cm} / 55 \mathrm{~cm} / 20 \mathrm{~cm} \times 45 \mathrm{~cm}$ ) + one row sesame (30\%), $\mathrm{T}_{4}=$ mukhikachu (double row: $20 \mathrm{~cm} / 55 \mathrm{~cm} / 20 \mathrm{~cm} \times 45 \mathrm{~cm})+$ two row sesame (60\%) and $\mathrm{T}_{5}=$ mukhikachu (double row: $20 \mathrm{~cm} / 55 \mathrm{~cm} / 20 \mathrm{~cm} \times 45 \mathrm{~cm}$ ) + sesame broadcast $(100 \%)$. The experiment was laid out in a randomized complete block design with three replications. The unit plot size was $3 \mathrm{~m} \times 5 \mathrm{~m}$. Mukhikachu was the main crop and sesame as the intercrop in the study. The planting system maintained $55 \mathrm{~cm}$ spacing between two pairs and $20 \mathrm{~cm}$ spacing within the pairs of mukhikachu. BARI Mukhikachu 1 (Bilashi) and sesame variety BARI Til-3 were sown on 16 March 2009 and 3 March 2010, respectively. Sesame seeds were sown in line (30 $\mathrm{cm}$ apart row) following continuous seeding. The seed rate of sole sesame and mukhikachu was $7 \mathrm{~kg} / \mathrm{ha}$ and $700 \mathrm{~kg} / \mathrm{ha}$, respectively. The crop was fertilized with 60-30-50-20-2-2 kg/ha of N, P, K, S, Zn, and B for sole and intercrops. All 
nutrients except $\mathrm{N}$ were applied during final land preparation. $\mathrm{N}$ was applied in two equal splits at 45 and 100 days after emergence (DAE) at mukhikachu rows only. Weeding and other intercultural operations were done as per requirement of the crops. After emergence, sesame was thinned keeping plant to plant distance of $5 \mathrm{~cm}$. Earthing up of mukhikachu was done after harvesting sesame. Sesame was harvested on 8 June of 2009 and 7 June of 2010. Mukhikachu was harvested on 7 November 2009 and 31 October 2010, respectively. Data on yield and yield contributing characters were recorded and statistically analyzed. The mean values were adjudged by LSD test. Mukhikachu equivalent yield and economic analysis were done. Land equivalent ratio (LER) was computed according to Shaner et al. (1982) as follows:

LER $=\frac{\text { Intercropped yield of mukhikachu }}{\text { Sole crop yield of mukhikachu }}+\frac{\text { Intercropped yield of sesame }}{\text { sole crop yield of sesame }}$

Mukhikachu equivalent yield (MEY) was calculated as follows:

MEY = Yield of intercrop mukhikachu $+\frac{\text { yield of intercrop sesame } \times \text { price of sesame }}{\text { Price of mukhikachu }}$

The competitive ratio (CR) among different combinations was calculated using the following formulae (Chatterjee and Maiti, 1984):

$$
\begin{aligned}
& \mathrm{CR}_{\mathrm{m}}=\left(\mathrm{RY}_{\mathrm{m}} / \mathrm{RY}_{\mathrm{s}}\right) /\left(\mathrm{Z}_{\mathrm{m}} / \mathrm{Z}_{\mathrm{s}}\right) \\
& \mathrm{CR}_{\mathrm{s}}=\left(\mathrm{RY}_{\mathrm{s}} / \mathrm{RY}_{\mathrm{m}}\right) /\left(\mathrm{Z}_{\mathrm{s}} / \mathrm{Z}_{\mathrm{m}}\right)
\end{aligned}
$$

where,

$\mathrm{CR}_{\mathrm{m}}=$ competitive ratio of mukhikachu

$\mathrm{CR}_{\mathrm{s}}=$ competitive ratio of sesame (intercrop)

$\mathrm{RY}_{\mathrm{m}}=$ Relative yield of mukhikachu

$\mathrm{RY}_{\mathrm{s}}=$ Relative yield of sesame

$\mathrm{Z}_{\mathrm{m}} \mathrm{Z}_{\mathrm{s}}$ and are the sown/planting proportion of mukhikachu and sesame, respectively, in mixture.

\section{Results and Discussion}

\section{Yield contributing characters and yield of mukhikachu}

Yield contributing characters and yield of mukhikachu were influenced significantly by different crop combinations in both the years (Table 1). It was evident that all the yield contributing characters and yields in the intercrops decreased gradually with the increase of sesame population. This might be due to competition between mukhikachu and sesame crop for moisture, light and nutrients. Sole crop of mukhikachu showed higher yield and yield contributing characters which might be no competition with sesame. 
Table 1. Yield contributing characters and cormel yield of mukhikachu during 2008-09 and 2009-10.

\begin{tabular}{|c|c|c|c|c|c|c|c|c|c|c|c|c|}
\hline \multirow{2}{*}{ Treatments } & \multicolumn{2}{|c|}{$\begin{array}{c}\text { Secondary } \\
\text { corms /plant (no.) }\end{array}$} & \multicolumn{2}{|c|}{$\begin{array}{c}\text { Cormels/plant } \\
\text { (no.) }\end{array}$} & \multicolumn{2}{|c|}{$\begin{array}{c}\text { Weight of primary } \\
\text { corms/ plant (g) }\end{array}$} & \multicolumn{2}{|c|}{$\begin{array}{l}\text { Weight of secondary } \\
\text { corms /plant (g) }\end{array}$} & \multicolumn{2}{|c|}{$\begin{array}{c}\text { Weight of cormels/ } \\
\text { plant (g) }\end{array}$} & \multicolumn{2}{|c|}{ Cormel yield (t/ha) } \\
\hline & 2008-09 & 2009-10 & 2008-09 & 2009-10 & 2008-09 & 2009-10 & 2008-09 & $2009-10$ & 2008-09 & 2009-10 & 2008-09 & 2009-10 \\
\hline $\mathrm{T}_{1}$ & 5.12 & 4.80 & 17.50 & 15.00 & 99.96 & 114.7 & 101.10 & 102.7 & 286.06 & 180.3 & 14.01 & 10.88 \\
\hline $\mathrm{T}_{3}$ & 3.73 & 3.86 & 12.93 & 14.33 & 95.50 & 103.3 & 97.20 & 92.67 & 236.60 & 179.0 & 13.93 & 10.61 \\
\hline $\mathrm{T}_{4}$ & 3.60 & 3.66 & 12.90 & 14.20 & 96.10 & 100.0 & 96.06 & 90.67 & 232.70 & 172.3 & 13.83 & 10.58 \\
\hline $\mathrm{T}_{5}$ & 3.30 & 3.13 & 10.70 & 12.73 & 93.30 & 94.67 & 93.40 & 80.33 & 207.76 & 164.7 & 12.01 & 9.65 \\
\hline $\operatorname{LSD}_{(0.05)}$ & 0.77 & 0.58 & 1.68 & 1.12 & 3.98 & 9.64 & 4.69 & 9.00 & 14.03 & 8.12 & 0.91 & 0.76 \\
\hline CV (\%) & 9.86 & 7.56 & 6.23 & 3.98 & 2.07 & 4.68 & 2.42 & 4.92 & 2.92 & 2.34 & 3.42 & 3.66 \\
\hline
\end{tabular}

$\mathrm{T}_{1}=$ sole mukhikachu (double row: $20 \mathrm{~cm} / 55 \mathrm{~cm} / 20 \mathrm{~cm} \times 45 \mathrm{~cm}$ ), $\mathrm{T}_{3}=$ mukhikachu (double row: $20 \mathrm{~cm} / 55 \mathrm{~cm} / 20 \mathrm{~cm} \times 45 \mathrm{~cm}$ ) + one row sesame (30\%), $\mathrm{T}_{4}=$ mukhikachu (double row:20 cm/55 cm/20 cm $\left.\times 45 \mathrm{~cm}\right)+$ two row sesame $(60 \%)$ and $\mathrm{T}_{5}=$ mukhikachu (double row: $20 \mathrm{~cm} / 55 \mathrm{~cm} / 20 \mathrm{~cm} \times 45 \mathrm{~cm}$ ) + sesame broadcast $(100 \%)$. 
The highest number of secondary corms/plant was recorded in $\mathrm{T}_{1}$ (sole mukhikachu) treatment in both the years (Table 1). In intercropping treatments, the highest secondary corms/plant was found in mukhikachu double row + one row sesame (30\%). The lowest secondary corms/plant was observed in mukhikachu double row + sesame broadcast $(100 \%)$. Reduction of secondary corms/plant was found with the increased population of sesame. Similar trend was found in weight of primary corms/plant and weight of secondary corms/plant in both the years (Table 1). The highest cormels/plant (17.50 in 2008-09 and 15.00 in 2009-10) was recorded from the sole mukhikachu. In the intercrops, the highest cormels/plant (12.93 in 2008-09 and 14.33 in 2009-10) was obtained from mukhikachu double row + one row sesame $(30 \%)$ in both the years. The lowest cormels/plant (10.70 in 2008-09 and 12.73 in 2009-10) was found in mukhikachu double row + sesame broadcast (100\%). It might be due to interspecies competition for nutrients, soil moisture, plant population, light and other resources. The same trend was found in the case of weight of cormels/plant in both the years. The highest cormel weight/plant (286.06 g in 2008-09 and 180.30 $\mathrm{g}$ in 2009-10) was recorded from the sole mukhikachu. In intercrop combinations, maximum cormel weight/plant (236.60 g in 2008-09 and $179.0 \mathrm{~g}$ in 2009-10) was obtained from mukhikachu double row + one row sesame (30\%). The lowest cormel weight/plant (207.76 g in 2008-09 and $164.70 \mathrm{~g}$ in 2009-10) was observed in mukhikachu double row + sesame broadcast (100\%).

Sole mukhikachu gave the highest cormel yield 14.01 t/ha in 2008-09 and $10.88 \mathrm{t} /$ ha in 2009-10. In the intercrop combinations, mukhikachu double row + one row sesame (30\%) gave the maximum cormel yield (13.93 t/ha in 2008-09 and 10.61t/ha in 2009-10), which was followed by mukhikachu double row + two row sesame (60\%). The lowest yield (12.01 and 9.65t/ha) was found in mukhikachu double row + sesame broadcast $(100 \%)$ in both the years. This might be due to taller sesame plants having more population per unit area that suppressed the growth of mukhikachu and ultimately reduced the mukhikachu yield. The yield reduction of mukhikachu in intercropping combinations was 1$14 \%$ as compared to sole crops. The maximum reduction (11-14\%) was occurred in mukhikachu double row + sesame broadcast (100\%). These results were similar to the findings of Ahmed and Gunasena (1979) who reported that significant reduction in legume yield was observed in intercropping with nonlegume shady plants. Cormel yield and weight of cormels/plant of mukhikachu was produced higher in 2008-09 as compared to 2009-10. This might happen due to more rainfall (Total $1166 \mathrm{~mm}$ ) received by the crops that favoured better growth and development of the plant; ultimately increased the cormel yield and weight of cormels/plant.

\section{Yield contributing characters and yield of sesame}

The significant variation was found in case of branches/plant, capsules/plant and seed yield/ha, while plant height, seeds/capsule and 1000-seed weight were not 
significant (Table 2). The maximum number of branches/plant (5.10 in 2008-09 and 4.56 in 2009-10) was recorded in mukhikachu double row + one row sesame (30\%) followed by mukhikachu double row + two row sesame $(60 \%)$. The lowest number of branches/plant (3.50 in 2008-09 and 3.48 in 2009-10) was observed in mukhikachu double row + sesame broadcast (100\%). Increase of sesame population with mukhikachu, decreased the number of branches/plant.

The maximum number of capsules/plant (88.20 in 2008-09 and 99.1 in 200910) was recorded from the mukhikachu double row + one row sesame (30\%). Reduction in number of capsules/plant was found with increased plant population of sesame. Higher number of capsules/plant in the combination of lower population of sesame might be due to production of more branches in sesame plants as compared to the combination with dense population.

The highest seed yield of sesame (1.48 t/ha in 2008-09 and $1.27 \mathrm{t} / \mathrm{ha}$ in 200910) was recorded from the sole sesame. In the intercrops, the maximum seed yield (1.32 t/ha in 2008-09 and 1.21 t/ha in 2009-10) was found in mukhikachu double row + sesame broadcast $(100 \%)$ followed by mukhikachu double row + two row sesame $(60 \%)$. The lowest seed yield (0.58 t/ha and $0.69 \mathrm{t} / \mathrm{ha})$ was recorded in mukhikachu double row + one row sesame (30\%) in both the years because of the lowest plant population of sesame in per unit area. Sesame gave 8 to 54 percent higher yield in monoculture as compared to their corresponding intercropped yield.

\section{Competitive ratio (CR)}

Competitive ratio (CR) showed variation among the intercrop combinations indicating their differential competitive ability of component crops as influenced by varying population of sesame (Table 3.). Sesame showed better competitiveness over mukhikachu indicating higher CR values (1.05-1.54). The highest CR value of sesame was recorded in mukhikachu double row + one row sesame $(30 \%)\left(\mathrm{T}_{3}\right)$ showing a decreasing trend with the higher population of sesame. This was happened due to more intra-species competition at higher population of sesame. Similarly, the highest CR value of mukhikachu (0.94) was found in mukhikachu double row + sesame broadcast $(100 \%)\left(\mathrm{T}_{5}\right)$ exhibiting a decreasing trend with the increase of CR values of sesame. Lower difference of CR values indicated better utilization of growth resources. However, $\mathrm{T}_{4}$ treatment produced higher productivity in terms of mukhikachu equivalent yield (15.65 t/ha) with CR difference of 0.76 . Treatment $T_{5}$ failed to produce higher productivity although CR difference was minimum (0.11). This was probably occurred due to poorer yield of mukhikachu in broadcasting of sesame. The CR over 1 (unity) indicates the species as good competitor while less than 1 (unity) indicates the species as poor competitor when grown in association (Jedel et al., 1998). In this intercropping, sesame was the best competitor as compared to mukhikachu. 
Table 2. Yield contributing characters and seed yield of sesame during 2008-09 and 2009-10.

\begin{tabular}{c|ccc|c|c|c|c|c|c|c|c|c|c}
\hline Treatments & \multicolumn{2}{|c|}{$\begin{array}{c}\text { Plant height } \\
(\mathrm{cm})\end{array}$} & \multicolumn{2}{c|}{$\begin{array}{c}\text { Branches/ plant } \\
\text { (no.) }\end{array}$} & \multicolumn{2}{c|}{$\begin{array}{c}\text { Capsules/plant } \\
\text { (no.) }\end{array}$} & \multicolumn{2}{c|}{$\begin{array}{c}\text { Seeds/ capsule } \\
\text { (no.) }\end{array}$} & \multicolumn{2}{c|}{$\begin{array}{c}1000 \text {-seed } \\
\text { weight (g) }\end{array}$} & \multicolumn{2}{c}{$\begin{array}{c}\text { Seed yield } \\
\text { (t/ha) }\end{array}$} \\
\cline { 2 - 13 } & $2008-09$ & $2009-10$ & $2008-09$ & $2009-10$ & $2008-09$ & $2009-10$ & $2008-09$ & $2009-10$ & $2008-09$ & $2009-10$ & $2008-09$ & $2009-10$ \\
\hline $\mathrm{T}_{2}$ & 118.06 & 117.66 & 4.33 & 4.06 & 69.50 & 76.10 & 66.53 & 51.17 & 3.20 & 3.13 & 1.48 & 1.27 \\
$\mathrm{~T}_{3}$ & 118.40 & 119.98 & 5.10 & 4.56 & 88.20 & 99.10 & 67.60 & 52.43 & 3.34 & 3.26 & 0.58 & 0.69 \\
$\mathrm{~T}_{4}$ & 117.33 & 118.30 & 4.80 & 4.16 & 77.66 & 86.80 & 66.46 & 51.22 & 3.10 & 3.13 & 1.20 & 1.15 \\
$\mathrm{~T}_{5}$ & 117.46 & 116.78 & 3.50 & 3.48 & 57.50 & 60.74 & 63.53 & 50.55 & 2.90 & 3.00 & 1.32 & 1.21 \\
\hline LSD (0.05) & NS & NS & 0.71 & 0.52 & 9.85 & 5.95 & NS & NS & NS & NS & 0.16 & 0.09 \\
CV (\%) & 2.50 & 2.34 & 8.08 & 6.39 & 6.74 & 3.70 & 2.75 & 2.45 & 13.12 & 6.29 & 7.29 & 4.11 \\
\hline
\end{tabular}

\section{NS = Not significant}

$\mathrm{T}_{2}=$ sole sesame $(30 \mathrm{~cm} \times 5 \mathrm{~cm}), \mathrm{T}_{3}=$ mukhikachu (double row: $\left.20 \mathrm{~cm} / 55 \mathrm{~cm} / 20 \mathrm{~cm} \times 45 \mathrm{~cm}\right)+$ one row sesame $(30 \%)$, $\mathrm{T}_{4}=$ mukhikachu (double row: $20 \mathrm{~cm} / 55 \mathrm{~cm} / 20 \mathrm{~cm} \times 45 \mathrm{~cm})+$ two row sesame $(60 \%)$ and $\mathrm{T}_{5}=$ mukhikachu $($ double row:20 cm/55 cm/20 $\mathrm{cm} \times 45 \mathrm{~cm})+$ sesame broadcast $(100 \%)$. 
Table 3. Competitive ratio (CR) of sesame and mukhikachu.

\begin{tabular}{c|c|c|c}
\hline Treatments & $\begin{array}{c}\text { Competitive ratio of } \\
\text { mukhikachu }\end{array}$ & $\begin{array}{c}\text { competitive ratio of } \\
\text { sesame }\end{array}$ & Difference \\
\hline $\mathrm{T}_{1}$ & - & - & - \\
$\mathrm{T}_{2}$ & - & - & - \\
$\mathrm{T}_{3}$ & 0.64 & 1.54 & 0.90 \\
$\mathrm{~T}_{4}$ & 0.68 & 1.44 & 0.76 \\
$\mathrm{~T}_{5}$ & 0.94 & 1.05 & 0.11 \\
\hline $\mathrm{T}_{1}=$ sole mukhikachu (double row: $\left.20 \mathrm{~cm} / 55 \mathrm{~cm} / 20 \mathrm{~cm} \times 45 \mathrm{~cm}\right), \mathrm{T}_{2}=$ sole sesame $(30 \mathrm{~cm} \times 5 \mathrm{~cm})$, \\
$\mathrm{T}_{3}=$ mukhikachu (double row: $\left.20 \mathrm{~cm} / 55 / 20 \mathrm{~cm} \times 45 \mathrm{~cm}\right)+$ one row sesame $(30 \%), \mathrm{T}_{4}=$ \\
mukhikachu (double row: $20 \mathrm{~cm} / 55 \mathrm{~cm} / 20 \mathrm{~cm} \times 45 \mathrm{~cm})+$ two row sesame $(60 \%)$ and $\mathrm{T}_{5}=$ \\
mukhikachu (double row: $20 \mathrm{~cm} / 55 \mathrm{~cm} / 20 \mathrm{~cm} \times 45 \mathrm{~cm})+$ sesame broadcast $(100 \%)$.
\end{tabular}

\section{Mukhikachu equivalent yield (MEY)}

Mukhikachu equivalent yields were higher in all the intercrops (14.13-15.65 t/ha) than sole crop of mukhikachu (12.45 t/ha). Among the intercropping combinations, the highest mukhikachu equivalent yield (15.65 t/ha) was recorded from mukhikachu double row + two row sesame (60\%). Sole crop of sesame gave the lowest mukhikachu equivalent yield of $4.02 \mathrm{t} / \mathrm{ha}$ (Table 4). The results indicated that intercropping of sesame with mukhikachu gave higher productivity in terms of MEY as compared to sole crops. The results are in agreement with the findings of Mondal et al. (2004).

\section{Land equivalent ratio (LER)}

Land equivalent ratio (LER) of different intercropping combinations ranged from 1.44 to 1.83 indicating that the productivity increased $44-83 \%$ by intercropping. The highest land equivalent ratio (1.83) was obtained from the combination of mukhikachu double row + two row sesame (60\%). The LER value 1.83 indicated that by intercropping mukhikachu and sesame, a farmer could produce 12.45 (av. of two years) tons of mukhikachu and 1.38 (av. of two years) tons of sesame from one hectare of land instead of growing them separately in 1.83 hectares of land to obtain the same combined yield. The lowest LER (1.44) was observed from mukhikachu double row + one row sesame (30\%). The results revealed that LER $>1.00$ in intercropping rendered better productivity than their sole stand. The results are in agreement with the findings of Juskiw et al. (2000), Hashem et al. (1990), Hossain and Bari, (1996) and Quayyum et al. (1987).

\section{Economic evaluation}

Average of the two years' results revealed that the highest gross returns (Tk. 187585/ha), gross margin (Tk. 114265/ha), and benefit cost ratio (2.56) were 
observed from mukhikachu double row + two row sesame (60\%). Other two intercropped combination also showed higher monitory return than sole crop of mukhikachu and sesame (Table 4). Sole crop of sesame gave the lowest gross return (Tk. 48125/ha), gross margin (Tk. 19655/ha), and benefit cost ratio (1.69). In intercropping system, variation of cost of production was found among different combinations due to different prices of various inputs. The highest cost of cultivation (Tk.73800/ha) was recorded in mukhikachu double row + sesame broadcast (100\%) and the lowest from both the sole crops. Though less cost was involved in sole mukhikachu than intercropped but failed to show higher BCR because gross margin was higher due to combination of mukhikachu and sesame.

Table 4. Mukhikachu equivalent yield (MEY), land equivalent ratio (LER) and economics of intercropping sesame with mukhikachu (average of two years).

\begin{tabular}{c|cccc|c|c|c}
\hline Treatments & $\begin{array}{c}\text { MEY } \\
(\mathrm{t} / \mathrm{ha})\end{array}$ & LER & $\begin{array}{c}\text { Gross } \\
\text { return } \\
\text { (Tk/ha) }\end{array}$ & $\begin{array}{c}\text { Total cost } \\
(\mathrm{Tk} / \mathrm{ha})\end{array}$ & $\begin{array}{c}\text { Gross } \\
\text { margin } \\
(\mathrm{Tk} / \mathrm{ha})\end{array}$ & BCR \\
\hline $\mathrm{T}_{1}$ & 12.45 & 1.00 & 149340 & 68580 & 80760 & 2.18 \\
$\mathrm{~T}_{2}$ & 4.02 & 1.00 & 48125 & 28470 & 19655 & 1.69 \\
$\mathrm{~T}_{3}$ & 14.13 & 1.44 & 169465 & 72450 & 97015 & 2.34 \\
$\mathrm{~T}_{4}$ & 15.65 & 1.83 & 187585 & 73320 & 114265 & 2.56 \\
$\mathrm{~T}_{5}$ & 14.53 & 1.78 & 174235 & 73800 & 100435 & 2.36 \\
\hline
\end{tabular}

$\mathrm{T}_{1}=$ sole mukhikachu (double row: $20 \mathrm{~cm} / 55 \mathrm{~cm} / 20 \mathrm{~cm} \times 45 \mathrm{~cm}$ ), $\mathrm{T}_{2}=$ sole sesame $(30 \mathrm{~cm}$ $\times 5 \mathrm{~cm}$ ), $\mathrm{T}_{3}=$ mukhikachu (double row:20 cm/55 cm/20 cm $\times 45 \mathrm{~cm}$ ) + one row sesame (30\%), $\mathrm{T}_{4}=$ mukhikachu (double row:20 cm/55 cm/20 cm $\times 45 \mathrm{~cm}$ ) + two row sesame $(60 \%)$ and $\mathrm{T}_{5}=$ mukhikachu (double row: $20 \mathrm{~cm} / 55 \mathrm{~cm} / 20 \mathrm{~cm} \times 45 \mathrm{~cm}$ ) + sesame broadcast (100\%).

Price: Mukhikachu : Tk.12/kg and Sesame : Tk.35/kg

\section{Conclusion}

The study revealed that intercropping mukhikachu double row $(20 \mathrm{~cm} / 55 \mathrm{~cm} / 20$ $\mathrm{cm} \times 45 \mathrm{~cm})+$ two row (30 cm apart row) sesame (60\%) was found as the best intercrop combination in respect of mukhikachu equivalent yield (15.65 t/ha), gross return (Tk.187585/ha), gross margin (Tk.114265/ha), and benefit cost ratio (2.56).

\section{References}

Ahmed, S. and H. P. M. Gunasena. 1979. Nitrogen utilization and economics of some intercropping systems in tropical countries. Trop. Agric. 56(2) : 115-123 
AIS (Agricultural Information Service). 2011. Krishi Diary (Agricultural Diary). Agril. Infor. Service, Khamarbari, Farmgate, Dhaka 1215. p.1 (In Bangla).

Chatterjee, B. N. and S. Maiti. 1984. Cropping system. Raju Primlani, Oxford \& IBH pub.Co. 17 Park Street, Calcutta 700016. Pp. 124-130.

Hashem, A., A. F. M. Moniruzzaman and M. A. Akhtaruzzaman. 1990. Study on the productivity and profitability of potato intercropped with vegetable and relayed with onion. Bangladesh Agron. J. 3:39-13.

Hossain. M. A. and A. K. M. A. Bari. 1996. Effect of intercropping groundnut with garlic at varying plant population levels. Bangladesh Hort. 24(1\&2):29-34.

Jedel, P.E.; J.H. Helm and P. A. Burnett. 1998. Yield, quality and stress tolerance of barley mixture in central Alberta. Can. J. Plant Sci. 78:429-436.

Juskiw, P. E., J. H. Helm and D. F. Salmon. 2000. Competitive ability in mixture of small grain cereals. Crop Sci. 40:159-164.

Kurala, T. 1966. A study on the farming in USSR. Quarterly J. of Agro. Econ. 29(3):179205) Translated by IRRI.

Marshall, B. R. and W. Willey. 1983. Radiation interception and growth in an intercrop of pearl millet/groundnut. Field Crops Res. 7: 141-160.

Mondal, M. R. I., F. Begum and M. A. Hossain. 2004. Stydy on intercropping groundnut with garlic. Bangladesh J. Agril. Res. 29(3) : 357-364.

Pathick, D. C. and M. L. Malla. 1979. Study on the performance of crop legume under monoculture and intercrop combination, Sixth Annual Maize Development Workshop, Nepal, 1979.

Quayyum, M. A., M. E. Akanda and M. F. Karim. 1987. Row spacing and number of rows of chickpea grown in assocoation with maize. Bangladesh J. Agric. 12:223-230.

Rao, M. R., S. Ahmed, Gunasena and A. Alcantara. 1979. Multilocational evaluation of productivity and stability of some cereal legume intercropping systems. East West Centre, Honolulu, Hawii: 123-160.

Shaner, W. W., P. F. Philipp and W. B. Schemehl. 1982. The equivalent ratio, farming systems research and development. West View Press. USA. Pp. 323-324.

Yahock, J. Y. 1979. Crops and cropping pattern of the Savanna region of Nigeria. The Kaduna situation. Paper presented at the international intercropping workshop, January, 10-13, 1779. ICRIST, Hyderabad, India. 